\title{
Special admission: how college sports recruitment favors white, suburban athletes
}

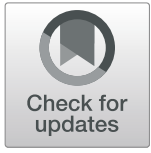

Angela Judge-Stasiak

\author{
Correspondence: ajudge@ucalgary. \\ ca \\ Werklund School of Education at \\ the University of Calgary, Calgary, \\ Canada
}

Book Details.

Hextrum, K. (2021). Special admission: How college sports recruitment favors white, suburban athletes: Rutgers University Press.

Special admission: How college sports recruitment favors white, suburban athletes by Kirsten Hextrum offers a critical exploration of the political, economic, and cultural factors that shape and influence college admission. The author looks at issues and asks questions about the availability of both community resources and the impact on athletic college admission. Hextrum (2021) is an athlete, a former national champion rower and holds a $\mathrm{PhD}$ from the University of California. The author is currently an Assistant Professor at the University of Oklahoma and through roles in student support services for college athletes and academic publication has developed expertise on college athletic admissions.

Readers engaging with this book can expect to understand the historical, political, and economic factors that influence current practices in college admissions, with a critical analysis about the racial and gender exclusion of non-white athletes and the concentration of resources in white, suburban areas. Central themes within the work focus on race, gender, economic status, state control and access to resources as the contextual factors that influence the favoritism of white athletes in college admissions.

Hextrum (2021) locates the impact of race and the experiences of "violence, underand unemployment, and food and housing insecurity" (p. 2) that are disproportionately experienced in non-white communities due to political structures and state control. This suffering is accepted in American society and poverty is considered criminal or a personal failure which can only be redeemed through hard work and sacrifice which is grounded in false assumptions as it places the onus of success on the individual without recognizing the intersecting contexts which lead to poverty and crime. Throughout the book Hextrum (2021) offers examples of the significant historical events including the civil rights movement which influenced decision making in higher education. The impact of race in sports has been harmful and racial violence occurs in sport and is condoned when teammates, and coaches do not stop or change these behaviors.

Male-domination of sports creates gender segregation and prevents the participation in sport of anyone not identifying as a cisgender male athlete. Both gender and race

(c) The Author(s). 2021 Open Access This article is licensed under a Creative Commons Attribution 4.0 International License, which permits use, sharing, adaptation, distribution and reproduction in any medium or format, as long as you give appropriate credit to the original author(s) and the source, provide a link to the Creative Commons licence, and indicate if changes were made. The images or other third party material in this article are included in the article's Creative Commons licence, unless indicated otherwise in a credit line to the material. If material is not included in the article's Creative Commons licence and your intended use is not permitted by statutory regulation or exceeds the permitted use, you will need to obtain permission directly from the copyright holder. To view a copy of this licence, visit http://creativecommons.org/licenses/by/4.0/. The Creative Commons Public Domain Dedication waiver (http://creativecommons.org/publicdomain/zero/1.0/) applies to the data made available in this article, unless otherwise stated in a credit line to the data. 
segregation impact the access of women and non-white athletes to certain sports, so much so that even when there has been increased access and entry into college sports for both groups the access to sport coaching within the sport is still controlled by white men. The admissions practices within college sport legitimizes and sustains inequality.

The author centers the historical influences and the influence of state control on the college admissions process. These include colonial, white supremacist, capitalist, and neoliberal underpinnings (Hextrum, 2021). The power of the state is sustained by consent from other institutions including "education, sports, media, religion, and families" (p. 5). Specific to sports, the NCAA is the heart of power, control, and regulation. The title of one of the chapters in the book "Colonizers, Enslavers, and Patriarchs: The Founders of Higher Education" (p. 31) captures the worldview of where sport and colleges in America have been situated socially, politically, and culturally. These dynamics emphasize elite, white men which has become normalized, protected, and enabled across generations until recently.

Hextrum (2021) demonstrates the impact of race and class in college sports as occurring at the individual and group level that transcends an individual or family level. As such that state preserves and establishes unequal opportunities in communities through taxes, laws, and funding. This creates a myth that everyone has the freedom to choose and participate in what sport you want to compete in, when in fact others have a significant advantage and that choice and freedom remains restricted to dominant groups. Simultaneously "when the state offered greater legal protections to historically disenfranchised groups, it also preserved the legal mechanisms that elevated capitalism, whiteness, and masculinity" (p. 83). This has given rise to sports that are primarily white in composition and stereotypes about body type and capacity created false beliefs that excluded women and Black athletes. Interestingly, the interview participants shared early memories of sports that were not gender exclusive for sport or play, and the racial or gender binary occurred in the sphere of organized sports.

The historical, political, economic, and cultural influences of state control permit or restrict access to resources to participate and compete for college admission. This includes access to the money, opportunities for coaching, camps, transportation, supplies, and equipment required to participate in sport. Through state regulation and funding, priority was given to suburban areas that were racially and economically segregated and primarily white. State allocation of resources for schools and public spaces such as parks or swimming pools impact access to sport and opportunities to develop athletic skill. Despite the influence of the state funding and allocation of resources in certain communities, ideas about individual upward mobility, hard work, determination remain prevalent without awareness or connection to the context influencing an individual. These beliefs do not consider the capital and social investments athletes need across the individual, family, and community levels. Special athletic admission permits students into college based on athletic talent and not academic progress when access to private and elite sports or public recreation facilities is not equally provided in all communities to all individuals.

The process of assessments for admissions is currently geared toward white people who can afford the investment and training to grow in sport and yet there is perception that athleticism is evaluated objectively and transparently. Hextrum (2021) outlines that inequal access to physical and social capital that individual athletes having depended 
upon their physical and social location which favor those with resources and jobs that are flexible to allow the time, travel and commitment needed in the family unit to support emerging athletes to participate in sport. The spaces in which individuals grow up and what surrounds them with respect to safety, resources, play, housing, and employment retain the land control and resource acquisition of colonialism, concentrating athletic opportunities in suburban areas.

This book offers a unique exploration of special admissions in college athletics. The illusions of success in sport or the concept of sport mobility is particularly harmful in the Black community as it fails to see the multitude of factors that impact the journey to and through college. The importance of college admission, and broadly completing higher education impacts employment and earning capacity upon graduation. Despite the elite nature of higher education in the past, the increase in enrolment has not impacted all students equally and increased admissions does not mean increased diversity or representation of the population, generally and among athletes.

The spotlight on public scandals such as the Operation Varsity Blues (OVB) involved "celebrities, wealthy bankers, and chief executives, which drew public and press attention to the scandal" (p. ix). Public critique of the event made deviant the actions of the individuals involved without showing that the athletic admissions process was already inherently favored to white athletes with resources. Hextrum (2021) offers critical analysis to deconstruct myths that elevate or inaccurately perceive college admissions as objective, equitable or inclusive. This inquiry also makes explicit practices in applying for college admission including academic portfolios and unofficial visits that some individuals have more resources, connections, and support to engage in than others.

This book is clearly written and organized systematically to share stories in the context of different concepts, weaving interview participant responses through each chapter. The references included are indicative of doctoral studies and included a wide range of sources outlining historical, political, economic, gendered, racial, religious, cultural dimensions of examining the special admission process for college athletes. The study began in December 2016 and consisted of 47 life history interviews with athletes that ranged from one to three hours. Analysis of the findings of the study show admissions processes which favor white, middle-class athletes and included the social and institutional process that influence the admissions, where other studies have assumed that admissions is objective and individual.

The interviews and corresponding data reflected coaches have "almost unilateral discretion" (p. 16) in assessing athletic merit and that athletic merit is not neutral. The interview "participants described, in their own terms, their race, class, and gender positions" (p. 24) and the responses offered an opportunity to examine the impact of the state and the systems which influence individual and their families. Other publications which review the white dominance in sports and the exclusion of race and gender in sports have also offered critical analysis and reflection specific to certain sports, or sport culture. This book specifically looks at American history, colonization and white supremacy, and the intersection of state, political and funding decisions that control access to the resources, facilities and capital required to develop athletic talent for college admissions.

Hextrum (2021) offers an important contribution to the literature regarding the intersections and practices that influence and favor specific groups for admissions into 
college which confronts and challenges dominant myths about college athletes. It is a thoughtful and articulate account about how athletes are developed through "the state's interlacing of property, law, community, leisure, schools, and capital" (p. 148) and that the journey to sport is disproportionately impacted by food or housing insecurity or violence in non-white communities. It offers commentary on race neutrality which sustains the current system where the public accepts inequality because of the false assumption that athletes individually earn their position.

If one shortcoming could be identified from this book, it would be related to the task of creating the change needed for equity in the admission process, and not in the book itself. The time, effort, dialogue and reconceptualizing needed to shift current practice is long overdue, and yet the layers of systems, cultures and behaviors that need to shift and change are daunting. The harm and trauma of housing insecurity, income and employment, violence, and racism alongside the need to offer equity in access to resources and opportunities for recreation require a significant change for all to sport on equal ground. This is the work that readers are called upon to engage in.

This book offers the reader an opportunity to understand the multifaceted context which impact the individual prior to the college admissions process and how athletes are not objectively chosen, nor do they gain access through hard work and individual effort alone. There is a call to action to make the necessary changes and hope that this is possible with tangible ideas of how to do this work. Attention to ensuring capital that is physical, social, and cultural are considered and corresponding state control to allocate funding, resources, and opportunities proportionately across communities is required. Formal regulations in college admissions will take away the coach control, choice, and subjectivity in selecting the best athlete for a team. With eyes wide open, intergenerational transfer or privilege or trauma can be understood, and changes can be made to eliminate inequity including special admissions and scholarships. Regulation can increase transparency and accountability for admissions decisions. This could create a holistic admissions process that assess physical and cultural capital founded in "inclusiveness, transparency, and accountability" (p. 193). In closing, Hextrum (2021) offers hope that as historically oppressed groups complete hire education, these institutions will be part of future social change.

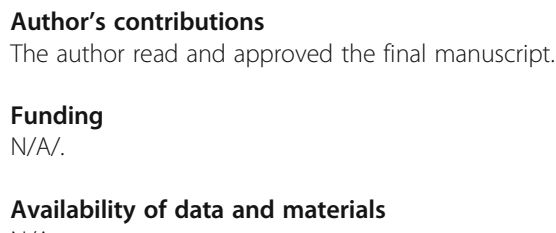

\section{Declarations}

Competing interests

Doctor of Education student working with Dr. Sarah Elaine Eaton.

Published online: 04 January 2022

Reference

Hextrum K (2021) Special admission: how college sports recruitment favors white, suburban athletes. Rutgers University press. https://doi.org/10.36019/9781978821248 